\title{
Prevalence and determinants of mother and newborn skin-to-skin contact in The Gambia: a secondary data analysis
}

\author{
Michael Ekholuenetale ${ }^{* *}$, Adeyinka Onikan² and Charity Ehimwenma Ekholuenetale ${ }^{3}$
}

\begin{abstract}
Background: Skin-to-skin contact (SSC) between mother and the newborn brings many benefits including its potential to promote the survival of the newborn. Nevertheless, it is a practice that is underutilized in many resource-constrained settings including The Gambia where a high rate of maternal and child mortality has been reported. In this study, we examined the prevalence and determinants of mother and newborn SSC in The Gambia.

Methods: We used secondary data from The Gambia Multiple Indicator Cluster Survey (MICS) - 2018. Data from 9205 women between 15-49 years who gave birth within 5 years of the survey was extracted for the analysis. Percentages and chi-square test were used for analyses. The significant variables from chi-square test were included in the multivariable binary logistic regression model to calculate the adjusted odds ratios (with corresponding 95\% $\mathrm{Cl}$ ) of the factors associated with mother and newborn SSC.

Results: The results of this study showed that the national prevalence of mother and newborn SSC was 35.7\%. Across local government areas; Mansakonko (47.8\%) and Kerewan (44.2\%) had the highest prevalence, while Basse (28.5\%) and Brikama (26.5\%) had the least prevalence of mother and newborn SSC in The Gambia. Based on results from the logit model, normal weight (at least $2.5 \mathrm{~kg}$ ) children were 1.37 times as likely to have mother and newborn SSC, compared with the low birthweight $(<2.5 \mathrm{~kg})$ children $(\mathrm{OR}=1.37 ; 95 \% \mathrm{Cl}: 1.05,1.78)$. In addition, there was 38\% increase in the odds of rural women who reported mother and newborn SSC, compared with urban women $(\mathrm{OR}=1.38 ; 95 \% \mathrm{Cl}: 1.06,1.79)$. Women who delivered at health facility were 3.35 times as likely to have mother and newborn SSC, compared with women who delivered at home (OR $=3.35 ; 95 \% \mathrm{Cl}$ : $2.37,4.75)$. Furthermore, women who initiated antenatal care (ANC) after the first trimester had $21 \%$ reduction in the odds of mother and newborn SSC, compared with women who initiated ANC within the first trimester $(\mathrm{OR}=0.79 ; 95 \% \mathrm{Cl}: 0.68,0.93)$.
\end{abstract}

Conclusion: The prevalence of mother and newborn SSC was low. In addition, geographical residence, birth weight, urban-rural residential status, place of delivery, and timing to ANC initiation were associated with mother and newborn SSC. There is a need to promote institutional based delivery using skilled birth attendance, promote early ANC initiation and healthy fetal growth.

Keywords: Newborn, The Gambia, Skin-to-skin, Thermal care, Mother

\footnotetext{
* Correspondence: mic42006@gmail.com

'Department of Epidemiology and Medical Statistics, Faculty of Public Health,

College of Medicine, University of Ibadan, Ibadan, Nigeria

Full list of author information is available at the end of the article
}

\section{Springer Open}

(- The Author(s). 2020 Open Access This article is licensed under a Creative Commons Attribution 4.0 International License, which permits use, sharing, adaptation, distribution and reproduction in any medium or format, as long as you give appropriate credit to the original author(s) and the source, provide a link to the Creative Commons licence, and indicate if changes were made. The images or other third party material in this article are included in the article's Creative Commons licence, unless indicated otherwise in a credit line to the material. If material is not included in the article's Creative Commons licence and your intended use is not permitted by statutory regulation or exceeds the permitted use, you will need to obtain permission directly from the copyright holder. To view a copy of this licence, visit http://creativecommons.org/licenses/by/4.0/. 


\section{Introduction}

Movement from the womb to the external world is a major event in the life of any individual. It is an event whereby the newborn adapts to the new world outside the mother's womb and needs close contact between mother and the newborn to initiate an avenue for bonding and to promote the neurological and physiological development of the child together with, make the mother confident in her capacity to nurse her child [1]. Mother and newborn SSC after delivery involves placing the newborn on the mother's chest for about $1 \mathrm{~h}$. The healthy full-term newborn placed in SSC, would commence breastfeeding within $1 \mathrm{~h}$ of age [2]. The World Health Organization (WHO) has provided a standard definition of mother and newborn SSC: "when the infant is placed prone on the mother's abdomen or chest in direct ventral-to-ventral skin-to-skin contact. Immediate skin-to-skin contact is done immediately after delivery, less than 10 minutes after birth. Early skin-to-skin contact was defined as beginning any time from delivery to 23 hours after birth. Skin-to-skin contact should be uninterrupted for at least 60 minutes" p.5 [3].

In spite of the efforts to improve children's survival in sub-Saharan Africa (SSA), the death of a child within the first month of life has remained unabated [4]. Approximately $99 \%$ of all newborn deaths occur in resourceconstrained settings, with about two-thirds occurring in Africa and Asia [5]. Improvements in neonatal survival rates are important for countries to meet the Sustainable Development Goals (SDGs) targets, which characterize global efforts toward improved health care-seeking behavior and equality in health care distribution. SDG-3 aims to ensure healthy lives and promote well-being for all at all ages [6]. Therefore, mother and newborn SSC becomes an essential practice to improve the health of the newborn [7]. It is against this backdrop that in the baby friendly hospital initiative (BFHI), there is a recommendation that newborns be placed in mother and newborn SSC for at least $1 \mathrm{~h} \mathrm{[8].}$

Generally, mother and newborn SSC helps in the newborn maintenance of blood glucose levels, temperature regulation, and metabolic adaptation. At birth, the newborn has a reduced capacity to generate heat, which results to a decline in body temperature. Hence, the maintenance of body temperature is paramount to the newborn at delivery. During mother and newborn SSC, there is a transfer of heat from the mother to her child, wherewith the mother's body temperature activates the child's sensory nerves, which in turn results in the child's relaxation, reduces the tone of the sympathetic nerves, dilation of skin vessels and increase in its temperature [9]. Albeit, hypothermia during the newborn period has remained a factor of morbidity and mortality in resource-constrained settings [10]. High prevalence of hypothermia has been reported in countries with the highest rate of newborn mortality, where hypothermia is increasingly gaining attention as a major intervention for newborn survival [11].

Besides the provision of several benefits to the newborn, mother and newborn SSC has also been linked with many benefits for mothers. For example, the secretion of oxytocin in mothers who practice SSC strengthens uterine contractions, which in turn aids the placenta to separate and the duration of the third stage of labor is shortened [12]. The third stage of labor entails separation and expulsion of the placenta and begins immediately after childbirth [13]. In many health facilities, proper management of the third stage of labor is a common practice to quicken the process, in which synthetic oxytocin, which makes the uterus strongly contract is administered. In a spontaneous, uncomplicated birth, it is reasonable to plan a physiological or natural third stage by utilizing the mother's own oxytocin [14]. As a simple, cost-effective and appropriate method, mother and newborn SSC is recommended to improve post-delivery care and potentially save the lives of mothers and newborns in particular [15].

Though WHO has recommended mother and newborn SSC, the separation of mothers and newborns is common in many health facilities whereby newborns are often placed under warmers or in cots [16]. In several SSA countries, mother and newborn SSC is rarely practiced [17], because mothers do not view SSC as important for keeping the baby warm after birth since newborns are usually taking away from their mothers immediately after birth, also due to prevailing cultural beliefs and practices that discourage mother and newborn SSC [18-20]. Moreover, health providers' factors such as lack of skilled personnel and time constraint, lack of awareness of the practice and its benefit have accounted for low coverage of mother and newborn SSC [21]. Very low rates were reported in Tanzania (less than 1\%) [22], Uganda and Mali (2\% each) [23, 24], Nigeria (10\%) [25], Ghana, (10\%) [20], and in Ethiopia (9\% and $13 \%)[26,27]$. To the best of our knowledge, there is no study in The Gambia that has reported the prevalence and determinants of mother and newborn SSC. We undertook this study to explore the prevalence and factors associated with mother and newborn SSC in The Gambia.

\section{Methods}

\subsection{Data source}

We used secondary data from The Gambia MICS2018. Data from 9205 women aged 15-49 years who gave birth in the last 5 years was extracted for analysis. The data was based on the questionnaire for individual women administered in each household to all women of 
reproductive age (15-49 years). The United Nations Children's Fund (UNICEF) developed the MICS program in the 1990s as an international household survey program to support countries in the collection of internationally comparable data on a wide range of indicators. MICS measure key indicators that allow countries to generate data for use in policies and programs, and to monitor progress toward the Sustainable Development Goals (SDGs), as well as the National Development Plan (NDP) of The Gambia and other internationally agreed upon commitments. In The Gambia, five Multiple Indicator Cluster Surveys have been conducted: 1996, 2000, 2006, 2010 and 2018. MICS6 contributed to the improvement of data and monitoring systems in The Gambia and strengthened technical expertise in the design, implementation, and analysis of such systems. The data can be downloaded online; https://mics.unicef.org/surveys.

\subsection{Sampling design}

The sample for The Gambia MICS 2018 was designed to provide estimates for a large number of indicators on the situation of children and women at the national level, for urban and rural areas, and for the eight local government areas: Banjul, Kanifing, Brikama, Mansakonko, Kerewan, Kuntaur, Janjanbureh, and Basse. The urban and rural areas within each local government area were identified as the main sampling strata and the sample of households was selected in two stages. Within each stratum, a specified number of census enumeration areas were selected systematically with probability proportional to size. After a household listing was carried out within the selected enumeration areas, a systematic sample of 20 households was drawn in each sample enumeration area. All enumeration areas selected were visited during the fieldwork period. The procedures and standard guidelines developed under the global MICS program were adapted to The Gambia MICS 2018 final questionnaires and used throughout the survey [28].

\subsection{Variables selection and measurement 2.3.1 Outcome variable}

Mother and newborn SSC was examined. The outcome was measured dichotomously as " 1 " if yes (had mother and newborn SSC) and "0" if otherwise (did not have mother and newborn SSC). Based on the definition of mother and newborn SSC, the outcome variable was measured in MICS-2018 using validated questionnaire for women in reproductive age (15-49 years).

\subsubsection{Explanatory variables}

Independent variables: household wealth quintile: poorest, poorer, middle, richer, and richest, was computed by MICS in a conventional approach from populationbased data using a set of household assets [29, 30]; child sex: male vs. female; ethnicity: Mandinka, Wollof, Fula, Jola, Sarahule, other groups and non-Gambians; health insurance coverage: insured vs. not insured; educational level: pre-primary or none, primary, secondary+, functionality difficulty: has functional difficulty vs. has no functional difficulty; total children ever born: 1-2, 3-4, 5+; marital status: currently married/in union, formerly married/in union, never married/in union; residential status: urban vs. rural; age at first marriage/union: $<18$ years, $18-20$ years, $20+$ years; estimation of overall happiness: very happy, somewhat happy, neither happy nor unhappy, somewhat unhappy, very unhappy; duration in residence: internal immigrant (lived in community $<5$ years) vs. native (lived in community for $5+$ years); maternal age (years): 15-19, 20-24, 25-29, 30-34, 35-39, 4044, 45-49; frequency of listening to radio or watching TV: not at all, less than once a week, at least once a week, almost every day; received ANC: yes vs. no; ANC visit initiation: early booking (within 1st trimester) vs. late booking (after 1st trimester); place of delivery: home vs. health facility; birth weight: low birthweight $(<2.5 \mathrm{~kg})$ vs. normal weight (at least $2.5 \mathrm{~kg}$ ); local government area: Banjul, Kanifing, Brikama, Mansakonko, Kerewan, Kuntaur, Janjanbureh, Basse. Some of these were selected as used by previous authors [31].

\subsection{Ethical consideration}

In this study, we utilized population-based dataset available in online with all identifier information removed. The survey protocol was approved by The Gambia Government and Medical Research Council Scientific Coordinating Committee (SCC) in March 2017. During the survey, verbal consent was obtained for each respondent participating and, for children age 15-17 years individually interviewed, adult consent was obtained in advance of the child's assent. All respondents were informed of the voluntary nature of participation and the confidentiality and anonymity of information.

\subsection{Statistical analysis}

Stata survey ('svy') module was used to adjust for stratification, clustering and sampling weights to compute the estimates of mother and newborn SSC. The collinearity testing approach adopted the correlation analysis to detect interdependence between variables. A cut-off of 0.7 was used to examine the multicollinearity known to cause major concerns [32]. No variable from the correlation matrix was removed in the model due to lack of multicollinearity. Percentages and chi-square test were used for analyses. All significant variables from chisquare test were included in the multivariable binary logistic regression model to calculate the adjusted odds ratios (with corresponding 95\% CI) of the factors associated with mother and newborn SSC. In addition, 
we obtained the marginal predictive effects of the determinants of mother and newborn SSC [33]. Statistical significance was determined at $p<0.05$. Data analysis was conducted using Stata Version 14 (StataCorp., College Station, TX, USA).

\section{Results}

The results of this study showed that the national prevalence of mother and newborn SSC was 35.7\%. However, across the local government areas, Mansakonko (47.8\%) and Kerewan (44.2\%) had the highest prevalence of SSC in The Gambia. Conversely, Brikama (26.5\%), Basse (28.5\%), and Banjul (29.9\%) had the least prevalence (Fig. 1).

Based on the results from Table 1, the percentage of mother and newborn SSC was about 38.6\% for poorest household wealth quintile, $41.5 \%$ in Wollof ethnic group, approximately $38.9 \%$ in rural area, $38.9 \%, 40.3 \%$, and $39.7 \%$ among those who booked early, gave birth at health facility and had normal weight baby respectively. See the table below for the details.

Based on the results, there was $38 \%$ increase in the odds of rural women to report mother and newborn SSC, compared with the urban women after adjusting for other covariates $(\mathrm{OR}=1.38 ; 95 \% \mathrm{CI}: 1.06,1.79)$. Mother and newborn SSC was significantly higher in Mansakonko local government area, when compared with Banjul local government area $(\mathrm{OR}=1.94 ; 95 \% \mathrm{CI}$ : $1.17,3.19)$. Women who delivered at health facility were 3.35 times as likely to have mother and newborn SSC, compared with women who delivered at home after adjusting for other covariates (OR $=3.35$; $95 \%$ CI: 2.37 , 4.75). Conversely, women who initiated ANC after the first trimester had $21 \%$ reduction in the odds of mother and newborn SSC, compared with women who initiated
ANC within the first trimester after adjusting for other covariates $(\mathrm{OR}=0.79 ; 95 \% \mathrm{CI}: 0.68,0.93)$. Women who had normal weight (at least $2.5 \mathrm{~kg}$ ) children were 1.37 times as likely to have mother and newborn SSC, compared with low birthweight $(<2.5 \mathrm{~kg})$ children after adjusting for other covariates (OR $=1.37$; $95 \%$ CI: 1.05 , 1.78). See Table 2 for the details.

In Table 3, marginal effect analysis was used to decipher the effects of the factors associated with mother and newborn SSC in The Gambia. It is clear, from the predictive marginal effects results, assuming the distribution of all factors remained the same among women, but every woman lived in rural residence or Mansakonko local government area, we would expect $42.0 \%$ and $52.0 \%$ mother and newborn SSC in The Gambia respectively. If instead the distribution of other maternal and child factors were as observed and other covariates remained the same among women, but all women had early ANC booking initiation, delivered at health facility or had normal weight baby, we would expect about $41.0 \%$ and $40.0 \%$ mother and newborn SSC in The Gambia respectively. In Table 3, we practically obtained the predictive marginal effects of the factors associated with mother and newborn SSC in The Gambia respectively. See Table 3 for the details.

\section{Discussion}

The study has become the foremost to report the prevalence of mother and newborn SSC in The Gambia. Here, only about one-thirds of women reported mother and newborn SSC. This result is higher than the SSC prevalence of previous studies in Tanzania and Ethiopia. Less than $1 \%$ of Tanzanian women reported early SSC [22], and the proportion of women in Ethiopia who had early SSC after childbirth was $9.2 \%$ and $28.1 \%$ [26, 31].

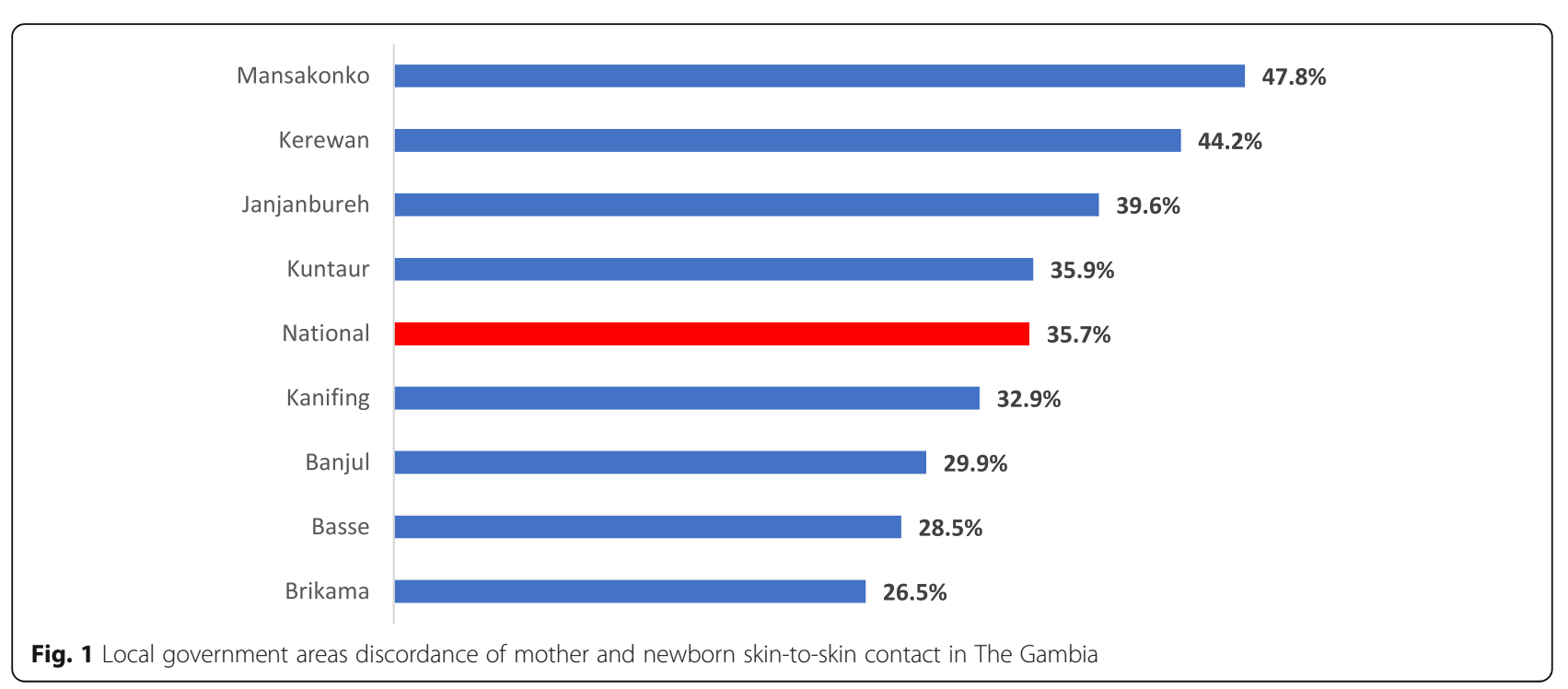


Table 1 Distribution of early mother and child skin-to-skin contact in The Gambia by selected socio-demographic and reproductive variables $(n=9205)$

\begin{tabular}{lll}
\hline Variable & $\begin{array}{l}\text { Number of } \\
\text { respondents (\%) }\end{array}$ & $\begin{array}{l}\text { Mother and newborn skin-to-skin contact \% } \\
\text { square test) }\end{array}$
\end{tabular}

\section{Sociodemographic profile}

Household wealth quintile $(n=9205)$

$0.003^{*}$

$\begin{array}{llll}\text { Poorest } & 2936(31.9) & 38.6 & 61.4 \\ \text { Second } & 2020(21.9) & 37.7 & 62.3 \\ \text { Middle } & 1656(18.0) & 31.8 & 68.2 \\ \text { Fourth } & 1335(14.5) & 32.0 & 68.0 \\ \text { Richest } & 1258(13.7) & 32.0 & 68.0\end{array}$

Ethnicity $(n=9205)$

Mandinka

2598 (28.2)

Wollof

Fula

Jola

Sarahule

Other groups

Non-Gambia

Residential area (9205)

Urban

Rural

Frequency of watching TV $(n=9202)^{\beta}$

$$
\begin{aligned}
& \text { Not at all } \\
& \text { Less than once a week } \\
& \text { At least once a week } \\
& \text { Almost everyday }
\end{aligned}
$$

Local government area $(n=9205)$

Banjul
Kanifing
Brikama
Mansakonko
Kerewan
Kuntaur
Janjanbureh
Basse

Reproductive profile

ANC visit initiation $(n=3759)^{\beta}$

$$
\begin{aligned}
& \text { Early booking } \\
& \text { Late booking }
\end{aligned}
$$

Place of delivery $(n=3791)^{\beta}$

$$
\text { Home }
$$

Health facility

Birth weight $(n=3016)^{\beta}$

$\begin{array}{lll}\text { Low birthweight } & 310(10.3) & 31.0 \\ \text { Normal } & 2706(89.7) & 39.7\end{array}$

4023 (43.7)

$5182(56.3)$

961 (10.4)

$1146(12.5)$

3205 (34.8)

604 (6.6)

1086 (11.8)

$1297(14.1)$

973 (10.6)

$1072(11.6)$

$1284(13.9)$

1217 (13.2)

$1672(18.2)$
61.4

62.3

68.2

68.0

68.0

$<0.001^{*}$

66.1

58.5

62.1

74.2

66.4

65.4

70.3

$700(76)$

30.2

38.9

$0.009^{*}$

$3890(42.3)$

37.6

35.5

38.3

31.9

29.9

32.9

26.5

47.8

44.2

35.9

39.6

28.5

$<0.001^{*}$

69.8

61.1

62.4

64.5

61.7

68.1

$<0.001^{*}$

70.1

67.1

73.5

52.2

55.8

64.1

60.4

71.5 5

$0.003^{*}$
.4
.2
8
8

.1
.5
.1
.2
6.4
.4
0.3

9.8

6.4
4.5
1.7
8.1

0.1

2

8

.4


Table 2 Multivariable logistic regression of the determinants of mother and newborn skin-to-skin contact in The Gambia

\begin{tabular}{llll}
\hline Variable & Adjusted odds ratio & $95 \% \mathrm{Cl}$ & $\boldsymbol{P}$ \\
\hline $\begin{array}{l}\text { Sociodemographic profile } \\
\text { Residential area }\end{array}$ & & & \\
$\quad$ Urban & 1.00 & & \\
$\quad$ Rural & 1.38 & $1.06-1.79$ & $0.017^{*}$ \\
Local government area & & & \\
$\quad$ Banjul & 1.00 & & \\
Kanifing & 1.16 & $0.78-1.74$ & 0.456 \\
Brikama & 0.89 & $0.58-1.36$ & 0.586 \\
Mansakonko & 1.94 & $1.17-3.19$ & $0.010^{*}$ \\
Kerewan & 1.23 & $0.76-2.00$ & 0.392 \\
Kuntaur & 1.08 & $0.65-1.77$ & 0.775 \\
Janjanbureh & 1.26 & $0.77-2.04$ & 0.357 \\
Basse & 0.80 & $0.49-1.31$ & 0.383
\end{tabular}

Reproductive profile

ANC visit initiation

$\begin{array}{llll}\text { Early booking } & 1.00 & & \\ \text { Late booking } & 0.79 & 0.68-0.93 & 0.003^{*}\end{array}$

\section{Place of delivery}

$\begin{array}{llll}\text { Home } & 1.00 & & \\ \text { Health facility } & 3.35 & 2.37-4.75<0.001^{*} \\ \text { Birth weight } & & & \\ \text { Low birthweight } & 1.00 & & \\ \text { Normal } & 1.37 & 1.05-1.78 & 0.019^{*}\end{array}$

*Significant at $p<0.05$; model was adjusted for; household wealth quintile, ethnicity, and frequency of watching TV

However, the finding was low as compared to studies in high-income countries in which SSC practice rate was up to $99.0 \%$ [34]. The possible reasons for the low prevalence of mother and newborn SSC immediately after childbirth could be due to lack of enlightenment or awareness about its importance and such health information can be obtained through mass media [35]. The strain in delivery, social distress, and family burden can be a major concern for women [36], and prevent uptake of SSC. Furthermore, spousal support could in no small measure enhance the uptake of SSC [37]. For example, in a previous study, husbands whose wives utilized skilled delivery care provided instrumental, emotional, and informational support to their wives during delivery and understood that medical support was paramount in positive childbirth outcome [38]. Similarly, health care providers can play vital role to provide support for mothers during labor as well as aid post-delivery care uptake including the uptake of mother and newborn SSC [39]. In The Gambia, women have reported that emotional support from nurses was valued as the most helpful during childbirth [40].
According to the results of an experimental study [41], contact through the skin between women and their newborns had immediate advantages including that it helps to improve early initiation of breastfeeding, support the success of exclusive breastfeeding, maintains normal body temperature, maintains heart rate, respiratory rate, and blood pressure normal [16, 41, 42]. These benefits underscore the need to improve mother and newborn SSC. Among the determinants of SSC identified in this study, health facility-based delivery resulted in higher odds of mother and newborn SSC. This is consistent with the findings from previous study and quite expected because modern maternal health care delivery is hinged on skilled birth attendance [43]. This brings to limelight the advantages of institutional delivery including that trained health care professionals could provide specific care and attention to newborn babies with special needs in order to improve their survival chances and reducing the risk of maternal mortality. The reduction in the odds of home delivery could be blamed on lack of skilled birth attendants to assist the women in the

Table 3 Marginal predictive model of the factors associated with mother and newborn skin-to-skin contact in The Gambia

\begin{tabular}{llll}
\hline Variable & Marginal effects & $95 \% \mathrm{Cl}$ & $\boldsymbol{P}$ \\
\hline $\begin{array}{l}\text { Sociodemographic profile } \\
\text { Residential area }\end{array}$ & & \\
$\quad$ Urban & 0.35 & $0.31-0.38$ & $<0.001^{*}$ \\
Rural & 0.42 & $0.39-0.45$ & $<0.001^{*}$ \\
Local government area & & & \\
Banjul & 0.36 & $0.27-0.45$ & $<0.001^{*}$ \\
Kanifing & 0.40 & $0.33-0.47$ & $<0.001^{*}$ \\
Brikama & 0.34 & $0.28-0.40$ & $<0.001^{*}$ \\
Mansakonko & 0.52 & $0.46-0.58$ & $<0.001^{*}$ \\
Kerewan & 0.41 & $0.36-0.46$ & $<0.001^{*}$ \\
Kuntaur & 0.38 & $0.33-0.43$ & $<0.001^{*}$ \\
Janjanbureh & 0.42 & $0.36-0.47$ & $<0.001^{*}$ \\
Basse & 0.32 & $0.27-0.36<0.001^{*}$
\end{tabular}

Reproductive profile

ANC visit initiation

\begin{tabular}{llll} 
Early booking & 0.41 & $0.39-0.44$ & $<0.001^{*}$ \\
Late booking & 0.36 & $0.34-0.39<0.001^{*}$ \\
Place of delivery & & & \\
Home & 0.18 & $0.13-0.22<0.001^{*}$ \\
Health facility & 0.41 & $0.39-0.42<0.001^{*}$ \\
$\begin{array}{l}\text { Birthweight } \\
\text { Low birthweight }\end{array}$ & 0.33 & $0.27-0.38<0.001^{*}$ \\
Normal & 0.40 & $0.38-0.41<0.001^{*}$ \\
\hline
\end{tabular}

*All factors were significant given $p<0.001$; model was adjusted for; household wealth quintile, ethnicity and frequency of watching TV 
practice or due to the fact that traditional birth attendant may lack the scientific information of SSC and its benefits.

Furthermore, women from rural area were found to have increased odds for mother and newborn SSC. This finding could be due to the fact that The Gambia is predominantly rural, as such, mother and newborn SSC could be higher in rural residence because it is possible that more health facilities are located in rural areas. In addition, women who had children with normal birth weight accounted for higher odds of mother and newborn SSC. This is consistent with the results of a previous study wherewith appropriate birth weight was associated with higher prevalence of skin to skin contact [44]. In this study, we found that proper fetal care during pregnancy resulting in optimal birthweight, was associated with improved mother and newborn SSC. These findings reinforce the hypothesis of strong influence of ANC practices and baby's conditions at birth in enhancing SSC between mother and newborn.

Conversely, women who reported late booking in ANC initiation had reduction in the odds of mother and newborn SSC. In a previous study, increased number of ANC visits was associated with higher SSC practice during the postpartum stay. Interestingly, early ANC initiation has been reported to be associated with higher number of ANC visits [45]. This explains why women with late ANC booking had reduction in the odds of mother and newborn SSC. When mothers attend more ANC visits or keep ANC appointments regularly, their awareness will increase thereby having good knowledge on the purpose of SSC and adherence to care for them and the newborn become more effective, also, this will result to large compliance, and finally leads mothers to provide SSC to their newborns. In addition, geographical location was significantly associated with mother and newborn SSC. This is consistent with the findings from a previous study [46]. The change in the odds of mother and newborn SSC in certain geographical location such as local government areas could be due to differences in availability, accessibility, and efficiency of health care delivery in such location. Again, previous maternal and newborn health care intervention in certain locations and exposure to certain behavior change communication could also explain or enhance the uptake of related health care practices.

\subsection{Strengths and limitations}

This study utilized large sample size, giving a national representative study sample. Such population-level findings for newborn care practices provide valuable knowledge for a health area where such data are practically lacking. Although the data are representative of the study area, it is likely that frequencies of newborn care behaviors vary between different geographies in The Gambia. For example, questions about delivery and newborn care practices could be restricted to women who had delivered within few years preceding the interview to maximize recall accuracy. The cross sectional nature of the present study prevents any causal inferences. The use of secondary data limited essential variables such as demand-side factors needed to understand in-depth newborn care practices. Although this study included all women who have given birth in the last 5 years to the survey, however, the large low response rate in maternal profile variables could have biased our estimates.

\section{Conclusion}

The prevalence of mother and newborn SSC was low. In addition, geographical residence, birth weight, urbanrural residential status, place of delivery, and timing to ANC initiation were associated with mother and newborn SSC. These suggest the importance of ANC as an appropriate time to inform pregnant women about mother and newborn SSC. However, the need to adopt measures that prioritize mother and newborn SSC in the delivery room is emphasized. Women should know about the importance of these practices and be encouraged to practice it. Also, there is a need to prioritize training of health providers on the implementation of essential newborn care including SSC. Community engagement is also needed to ensure that all women and their families understand the benefits of SSC.

\section{Abbreviations \\ ANC: Antenatal care; BFHI: Baby friendly hospital initiative; Cl: Confidence interval; MICS: Multiple indicator cluster survey; NDP: National development plan; OR: Odds ratio; SCC: Scientific coordinating committee; \\ SDG: Sustainable development goal; SSA: Sub-Saharan Africa; SSC: Skin-to- skin contact; UNICEF: United Nations Children's Fund; WHO: World Health Organization}

\section{Acknowledgements}

The authors appreciate the MICS project for the approval and access to the original data.

\section{Authors' contributions}

ME conceived and designed the study, performed data analysis, wrote the results, and discussed the findings. $\mathrm{AO}$ and CEE contributed to the review of literature, discussed the findings. All authors critically reviewed the manuscript for its intellectual content and approved the manuscript.

\section{Funding}

This research received no grant from any funding agency in the public commercial, or not-for-profit sectors.

\section{Availability of data and materials}

Unique identifiers such as location and names collected during interviews were removed from datasets to ensure confedintiality. These anonymized data files are made available and can be freely downloaded for legitimate research purposes on; https://mics.unicef.org/surveys.

Ethics approval and consent to participate

Ethics approval for this study was not required since the data is secondary and is available in the public domain. 


\section{Consent for publication}

Not applicable

\section{Competing interests}

The authors declare that the research was conducted in the absence of any commercial or financial relationships that could be construed as a potential conflict of interest.

Author details

'Department of Epidemiology and Medical Statistics, Faculty of Public Health, College of Medicine, University of Ibadan, Ibadan, Nigeria. ${ }^{2}$ Project Management Unit, Management Sciences for Health, Abuja, Nigeria. ${ }^{3}$ Department of Economics, Benin Study Center, National Open University of Nigeria, Benin City, Nigeria.

\section{Received: 27 November 2019 Accepted: 17 July 2020}

\section{Published online: 12 August 2020}

\section{References}

1. Marín Gabriel MA, Llana Martín I, López Escobar A, Fernández Villalba E, Romero Blanco I, Touza PP. Randomized controlled trial of early skin-to-skin contact: effects on the mother and the newborn. Acta Paediatr. 2010;99(11): $1630-4$.

2. Moore ER, Anderson GC, Bergman N, Dowswell T. Early skin-to-skin contact for mothers and their healthy newborn infants. Cochrane Database Syst Rev. 2012;5.

3. World Health Organization. Protecting, promoting, and supporting breastfeeding in facilities providing maternity and newborn services [Internet]. 2017. http://www.ncbi.nlm.nih.gov/books/NBK487819/.

4. Liu L, Johnson HL, Cousens S, Perin J, Scott S, Lawn JE, et al. Global, regional, and national causes of child mortality: an updated systematic analysis for 2010 with time trends since 2000. The Lancet. 2012;379(9832): 2151-61.

5. Lawn JE, Cousens S, Zupan J. Lancet Neonatal Survival Steering Team. 4 million neonatal deaths: when? Where? Why? The lancet. 2005;365(9462): 891-900.

6. Lynch T. United Nations Sustainable Development goals: promoting health and well-being through physical education partnerships. Cogent Education [Internet]. 2016 Jun 7. https://www.cogentoa.com/article/10.1080/2331186 X.2016.1188469.

7. UNICEF. Guide to the Baby Friendly Initiative Standards. 2nd edition. UK: UNICEF; 2017. p 26.

8. World Health Organization, UNICEF. Baby-friendly hospital initiative: revised, updated and expanded for integrated care. [Internet]. 2009. http://www. ncbi.nlm.nih.gov/books/NBK153471/.

9. Jonas W, Wiklund I, Nissen E, Ransjö-Arvidson A-B, Uvnäs-Moberg K. Newborn skin temperature two days postpartum during breastfeeding related to different labour ward practices. Early Human Development. 2007; 83(1):55-62.

10. Darmstadt GL, Bhutta ZA, Cousens S, Adam T, Walker N, de Bernis L, et al. Evidence-based, cost-effective interventions: how many newborn babies can we save? Lancet. 2005;365(9463):977-88.

11. Ellis M, Manandhar N, Shakya U, Manandhar DS, Fawdry A, Costello AM. Postnatal hypothermia and cold stress among newborn infants in Nepal monitored by continuous ambulatory recording. Archives of Disease in Childhood - Fetal and Neonatal Edition. 1996;75(1):F42-5.

12. Kiss A, Mikkelsen JD. Oxytocin--anatomy and functional assignments: a mini review. Endocr Regul. 2005;39(3):97-105.

13. Buckley SJ. Leaving well alone in the third stage of labour. Midwifery Today Int Midwife. 2011-2012 Winter:(100):30-2.

14. Burke C. Active versus expectant management of the third stage of labor and implementation of a protocol. J Perinat Neonatal Nurs. 2010;24(3):215-28.

15. Boundy EO, Dastjerdi R, Spiegelman D, Fawzi WW, Missmer SA, Lieberman E, et al. Kangaroo mother care and neonatal outcomes: a meta-analysis. Pediatrics. 2016:137(1):e20152238.

16. Ferrarello D, Hatfield L. Barriers to skin-to-skin care during the postpartum stay. MCN Am J Matern Child Nurs. 2014:39(1):56-61.

17. Bee M, Shiroor A, Hill Z. Neonatal care practices in sub-Saharan Africa: a systematic review of quantitative and qualitative data. J Health Popul Nutr. 2018;37(1):9
18. Adejuyigbe EA, Bee MH, Amare Y, Omotara BA, Iganus RB, Manzi F, et al. Why not bathe the baby today?: a qualitative study of thermal care beliefs and practices in four African sites. BMC Pediatr. 2015;15(1):156.

19. Shamba D, Schellenberg J, Hildon ZJ-L, Mashasi I, Penfold S, Tanner M, et al. Thermal care for newborn babies in rural southern Tanzania: a mixedmethod study of barriers, facilitators and potential for behaviour change. BMC Pregnancy Childbirth. 2014;14(1):267.

20. Hill Z, Tawiah-Agyemang C, Manu A, Okyere E, Kirkwood BR. Keeping newborns warm: beliefs, practices and potential for behaviour change in rural Ghana. Tropical Medicine \& International Health. 2010;15(10):1118-24.

21. Alenchery AJ, Thoppil J, Britto CD, de Onis JV, Fernandez L, Suman Rao PN. Barriers and enablers to skin-to-skin contact at birth in healthy neonates - a qualitative study. BMC Pediatr. 2018;18(1):48.

22. Penfold S, Hill Z, Mrisho M, Manzi F, Tanner M, Mshinda H, et al. A large cross-sectional community-based study of newborn care practices in southern Tanzania. PLoS One. 2010;5(12):e15593.

23. Waiswa P, Peterson S, Tomson G, Pariyo GW. Poor newborn care practices a population based survey in eastern Uganda. BMC Pregnancy Childbirth. 2010;10(1):9.

24. Save the Children. Newborn care in Mali: results of a baseline survey. Save the Children. Addis Ababa. 2008 report; 6p. https://www. healthynewbornnetwork.org/hnn-content/uploads/Mali-Baseline-Sum_0.pdf.

25. Singh K, Khan SM, Carvajal Aguirre L, Brodish P, Amouzou A, Moran A. The importance of skin-to-skin contact for early initiation of breastfeeding in Nigeria and Bangladesh. J Glob Health. 2017;7(2):020505.

26. Callaghan-Koru JA, Estifanos AS, Sheferaw ED, de Graft-Johnson J, Rosado C, Patton-Molitors R, et al. Practice of skin-to-skin contact, exclusive breastfeeding and other newborn care interventions in Ethiopia following promotion by facility and community health workers: results from a prospective outcome evaluation. Acta Paediatr. 2016:105(12):e568.

27. Callaghan-Koru JA, Seifu A, Tholandi M, de Graft-Johnson J, Daniel E, Rawlins B, et al. Newborn care practices at home and in health facilities in 4 regions of Ethiopia. BMC Pediatr. 2013;13(1):198.

28. UNICEF. "MICS6 TOOLS", The standard MICS6 data collection application. UNICEF, 2017. https://mics.unicef.org/tools.

29. Hruschka DJ, Gerkey D, Hadley C. Estimating the absolute wealth of households. Bull World Health Organ. 2015;93(7):483-90.

30. Rutstein SO, Staveteig S. Making the demographic and health surveys wealth index comparable. 2014; DHS Methodological Reports No. 9. Rockville, Maryland, USA: ICF International.

31. Bedaso A, Kebede E, Adamu T. Assessment of skin-to-skin contact (SSC) during the postpartum stay and its determinant factors among mothers at public health institutions in Ethiopia. BMC Res Notes. 2019;12(1):136.

32. Midi H, Sarkar SK, Rana S. Collinearity diagnostics of binary logistic regression model. Journal of Interdisciplinary Mathematics. 2010;13(3):253-67.

33. Williams R. Using the margins command to estimate and interpret adjusted predictions and marginal effects. The Stata Journal. 2012;12(2):308-31.

34. Abdulghani N, Edvardsson K, Amir LH. Worldwide prevalence of motherinfant skin-to-skin contact after vaginal birth: a systematic review. PLoS ONE. 2018;13(10):e0205696.

35. Dutta MJ. Health information processing from television: the role of health orientation. Health Commun. 2007;21(1):1-9.

36. Sawyer A, Ayers S, Smith H, Sidibeh L, Nyan O, Dale J. Women's experiences of pregnancy, childbirth, and the postnatal period in The Gambia: a qualitative study. Br J Health Psychol. 2011 Sep;16(3):528-41.

37. Timur Taşhan S, Duru Y. Views on spousal support during delivery: a Turkey experience. BMC Pregnancy Childbirth. 2018;18(1):142.

38. Story WT, Burgard SA, Lori JR, Taleb F, Ali NA, Hoque DE. Husbands' involvement in delivery care utilization in rural Bangladesh: a qualitative study. BMC Pregnancy Childbirth. 2012;12(1):28.

39. Najafi FT, Roudsari RL, Ebrahimipour $\mathrm{H}$. The best encouraging persons in labor: a content analysis of Iranian mothers' experiences of labor support. PLOS ONE. 2017;12(7):e0179702.

40. Mbye M, Tsay SL, Chao CH, Lin KC. Perceptions of midwife support during labour and delivery in Gambia. Afr J Midwifery Womens Health. 2011;5(2).

41. Safari K, Saeed AA, Hasan SS, Moghaddam-Banaem L. The effect of mother and newborn early skin-to-skin contact on initiation of breastfeeding, newborn temperature and duration of third stage of labor. Int Breastfeed J. 2018:13(1):32

42. Svensson KE, Velandia MI, Matthiesen A-ST, Welles-Nyström BL, Widström AME. Effects of mother-infant skin-to-skin contact on severe latch-on problems in older infants: a randomized trial. Int Breastfeed J. 2013;8(1):1. 
43. Pagel C, Prost A, Hossen M, Azad K, Kuddus A, Roy SS, et al. Is essential newborn care provided by institutions and after home births? Analysis of prospective data from community trials in rural South Asia. BMC Pregnancy Childbirth. 2014;14(1):99.

44. e Silva CM, Pereira SCL, Passos IR, dos Santos LC. Factors associated with skin to skin contact between mother/son and breastfeeding in the delivery room. Revista de Nutrição. 2016;29(4):457-71.

45. Terefe AN, Gelaw AB. Determinants of antenatal care visit utilization of child-bearing mothers in Kaffa, Sheka, and Bench Maji Zones of SNNPR, Southwestern Ethiopia. Health Services Research and Managerial Epidemiology. 2019;6.

46. Menezes MAS, Gurgel R, Bittencourt SDA, Pacheco VE, Cipolotti R, do Carmo Leal M. Health facility structure and maternal characteristics related to essential newborn care in Brazil: a cross-sectional study. BMJ Open. 2018; 8(12).

\section{Publisher's Note}

Springer Nature remains neutral with regard to jurisdictional claims in published maps and institutional affiliations.

\section{Submit your manuscript to a SpringerOpen ${ }^{\circ}$ journal and benefit from:}

- Convenient online submission

- Rigorous peer review

- Open access: articles freely available online

High visibility within the field

- Retaining the copyright to your article

Submit your next manuscript at $\boldsymbol{\nabla}$ springeropen.com 